\title{
Case Report: Primary Urothelial Carcinoma of Ureteral Stump Following Radical Nephrectomy for Renal Cell Carcinoma*
}

\author{
Donghai Teng\#, Guimin Huang, Kaixiang Wang, Jianping Du \\ Department of Urology, The People’s Hospital of Leshan, Leshan, China. \\ Email: \#tengdh@126.com
}

Received March 28 ${ }^{\text {th }}, 2013$; revised April 2 ${ }^{\text {nd }}, 2013$; accepted May 2 ${ }^{\text {nd }}, 2013$

Copyright (C) 2013 Donghai Teng et al. This is an open access article distributed under the Creative Commons Attribution License, which permits unrestricted use, distribution, and reproduction in any medium, provided the original work is properly cited.

\begin{abstract}
PUC is common in the urinary tract. It may occur in the urinary bladder and the collecting system of the upper urinary tract, such as the renal pelvis and ureter. However, PUC of ureteral stump after a nephrectomy is rare, and it's even rarer in patients undergoing a radical nephrectomy for RCC. We describe a female patient with painless gross hematuria that was secondary to PUC of ureteral stump after a radical nephrectomy for RCC diagnosed 6 years ago. We discuss the etiology, diagnosis and treatment for PUC of ureteral stump following radical nephrectomy for RCC.
\end{abstract}

Keywords: Urothelial Carcinoma; Ureter; Nephrectomy; Renal Cell Carcinoma

\section{Introduction}

A PUC of ureteral stump can be defined as a urothelial carcinoma occurring in the closed ureteral stump after a nephrectomy for either benign or malignant disease other than a urothelial carcinoma. The ipsilateral ureteral stump is usually left as short as possible due to the requirement of radical nephrectomy. And the occurrence of malignant tumor of the ureteral stump following nephrectomy is also extremely rare. Therefore, the remaining ureteral stump does not receive routine examination during follow-up. Nagatsuma, K. et al. [1] reported a male patient presented with microscopic hematuria during a routine checkup after undergoing a radical nephrectomy for RCC. The histologic diagnosis of the patient was transitional carcinoma of the ureteral stump. We report the case of a female patient with PUC developed in a remnant ureter following radical nephrectomy for RCC.

\section{Case Report}

A 63-year-old Chinese female with painless gross hematuria visited the Department of Urology of our hospital in 2012. She had been diagnosed with type 2 diabetes mellitus for 8 years and has regular follow-up and well-con-

\footnotetext{
*Conflict of interest: None declared.

${ }^{*}$ Corresponding author.
}

trolled blood glucose level. In 2006 (six years ago), a routine ultrasound examination detected a right renal tumor. She underwent radical nephrectomy in our hospital. The pathological reports revealed a RCC of stage $\mathrm{T}_{2 \mathrm{a}} \mathrm{N}_{0} \mathrm{M}_{0}$, which covered the cortex and medulla with central areas of necrosis and hemorrhage, measuring 8.0 $\mathrm{cm} \times 6.5 \mathrm{~cm} \times 5.0 \mathrm{~cm}$. The calyx segment of the collecting system was also included. Her ureter was not dilated and its mucosa was not remarkable. Fortunately, her ureter was free from malignant lesions. She received regular follow-up post-operatively.

In August 2012, she had one episode of painless gross hematuria which lasted for 7 days. And clot formation was noted in her urine. On physical examination, she had a scar about $20 \mathrm{~cm}$ on her right flank. Urinalysis showed microscopic hematuria. Blood routine test revealed mild anemia (RBC $3.32 \times 10^{12} / \mathrm{L}$, HGB $97.00 \mathrm{~g} / \mathrm{L}$ ). The level of FBG was $7.23 \mathrm{mmol} / \mathrm{L}$. And other laboratory results were within normal range. Ultrasound examination, intravenous urography and CT showed a normal left urinary tract and no signs of recurrence of the right RCC. Unexpectedly, CT revealed a solid mass in the distal region of the right ureteral stump and the mass protruding through right ureteral orifice (Figure 1). The biopsy was taken during cystoscopy and pathologic examination reports a WHO grade 1 urothelial carcinoma (Figure 2(a)). Bone scan showed no evidence of distant metastasis. 


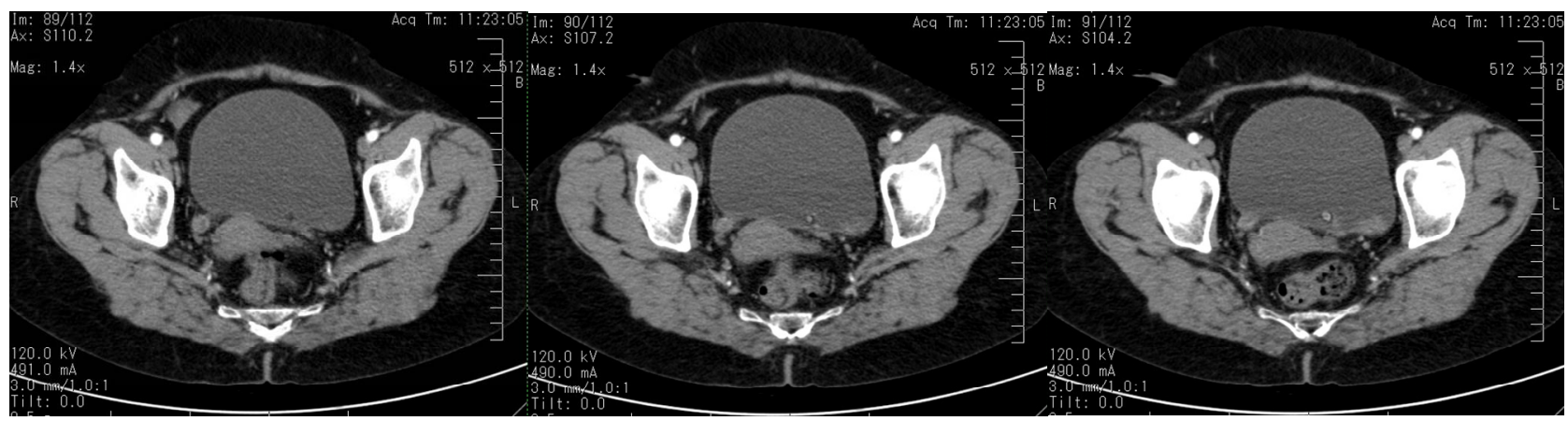

(a)

(b)

(c)

Figure 1. CT showed a solid mass in the distal region of the right ureteral stump. (a) The mass in the right urethral stump; (b) The mass in the ureterovesical junction of the remnant ureter; (c) The mass protruding through right ureteral orifice.

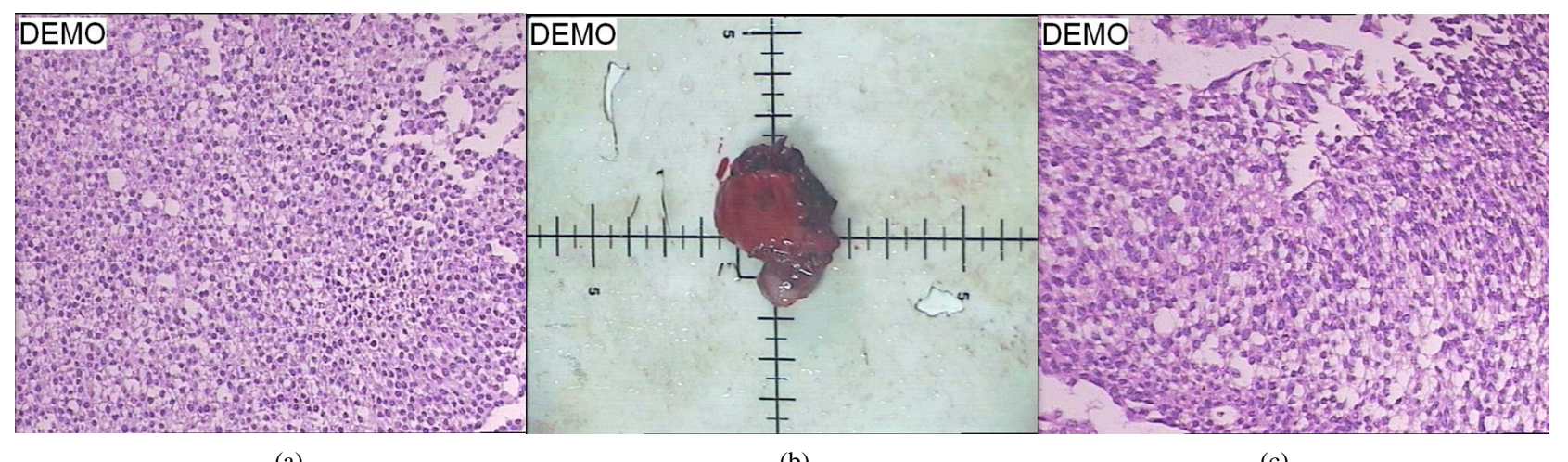

(a)

(b)

(c)

Figure 2. Pathologic features of the tumor. (a) Microscopic appearance of biopsy specimen (grade 1) (H\&E $\times 100)$; (b) Gross appearance; (c) Microscopic appearance of post-operative specimen (grade 1 to 2) (H\&E × 100).

The patient underwent right ureterectomy with cuff excision of the bladder. The gross specimen showed a greywhite neoplasm, measuring $3.0 \mathrm{~cm} \times 1.0 \mathrm{~cm} \times 1.0 \mathrm{~cm}$, just above the ureterovesical junction of the remnant ureter (Figure 2(b)). And the post-operative pathological examination revealed WHO grade 1 to 2 urothelial carcinoma of the ureter (Figure 2(c)). The main tumor infiltrated into the subepithelial connective tissue $\left(\mathrm{T}_{1}\right)$. The post-operative course was uneventful. She was discharged on the 6th post-operative day and received intravesical instillation of mitomycin $C$ to prevent recurrence once a week for 6 weeks and then once a month for 6 months. She is doing well and has been tumor-free for 12 months.

\section{Discussion}

The incidence of PUC in the ureter is uncommon and represents approximately $5 \%$ of all urothelial carcinomas. It often occurs in the lower third of the ureter and the recurrence rate is relatively high [2]. A primary tumor of the ureteral stump after a nephrectomy is infrequently observed. Moreover, a PUC of the ureteral stump after a nephrectomy for RCC is extremely rare. Wei-Ping Chang et al. [3] reviewed the literature thoroughly and found only seven cases of ureteral stump carcinoma after a nephrectomy for RCC had been previously reported before 2012. They reported the eighth observed case and it's also the first case in Taiwan. Our case is the second female case in the literature. What makes these patients suffer from RCC and PUC successively? RCC is a common renal parenchymal malignant tumor and originates from the proximal renal tubular epithelium in the renal cortex. Smoking, genetic mutation and obesity have been implicated to the occurrence of RCC [4]. PUC is common in the urinary tract. It may occur in the urinary bladder and the collecting system of the upper urinary tract, such as the renal pelvis and ureter. The causes of PUC include smoking, genetic mutations and occupational exposure to chemicals, dyes, rubbers, petroleum, leathers and printing materials [5]. It is still an unveiled issue why malignant tumors occur in the closed ureteral stump. Several etiologic factors in the pathogenesis of genitourinary malignant tumors including chronic inflammation, leukoplakia, and exposure to carcinogenic substances, have been postulated [6]. Suzuki, T. et al. [7] suggested genetic or environmental factors may have contributed to 
the etiology of the ureteral stump tumor. Long-term multiple use of Chinese herbal drugs could be one of the important risk factors for developing PUC [3,8]. Our case had no history of smoking and occupational exposure factors. She had been diagnosed with type 2 diabetes mellitus for 8 years and has regular follow-up and wellcontrolled blood glucose level. The relationship between diabetes mellitus and RCC or PUC remains unknown. We infer that no longer exposure to chemical carcinogens in the urine after nephrectomy contributes to the low possibility of developing cancer of ureteral stump. And genetic hypersensitivity, mutation or pharmacological carcinogenetic effects provide other possibilities for cancer development.

The ipsilateral ureteral stump is usually left as short as possible due to the requirement of radical nephrectomy. And the occurrence of malignant tumor of the ureteral stump following nephrectomy is also extremely rare. Clinically, the remaining ureteral stump does not receive routine examination during follow-up. Furthermore, the ureteral stump is not visualized upon urography. Therefore, the successful diagnosis may not be achieved easily. In this situation suspicion is important and other diagnostic tool such as CT or retrograde ureterography can be helpful [9]. Nagatsuma, K. et al. [1] suggested the ureteral stump must be correctly evaluated using retrograde ureterography in any patient with hematuria in the follow-up period after nephrectomy for RCC. In our case, the intravenous urography did not show any evidence of abnormality in right residual urinary tract. And CT posed a pivotal role for the detection of the tumor.

As for the treatment for PUC of the ureteral stump, we suggest that it should obey the principles for urothelial carcinoma of ureter. The ureteral stump should be resected completely with a bladder cuff. And intravesical instillation of chemotherapeutic drug is suggested to prevent recurrence.

\section{REFERENCES}

[1] K. Nagatsuma, M. Tachibana, A. Miyakawa, H. Asanuma and M. Murai, "Transitional Cell Carcinoma of Ureteral Stump after Radical Nephrectomy for Renal Cell Carcinoma,” International Journal of Urology, Vol. 6, 1999, pp. 627-629. doi:10.1046/j.1442-2042.1999.00117.x

[2] K. S. Pohar and J. Sheinfeld, "When Is Partial Ureterectomy Acceptable for Transitional-Cell Carcinoma of the Ureter?” Journal of Endourology, Vol. 15, No. 4, 2001, pp. 405-409. doi:10.1089/089277901300189439

[3] W.-P. Chang, T.-M. Chien, Y.-S. Wang, et al., "Cox-2 Gene Overexpression in Ureteral Stump Urothelial Carcinoma Following Nephrectomy for Renal Cell Carcinoma: A Case Report," Journal of Medical Case Reports, Vol. 6, 2012, pp. 44-50. doi:10.1186/1752-1947-6-44

[4] J. L. Beebe-Dimmer, J. S. Colt, J. J. Ruterbusch, et al., "Body Mass Index and Renal Cell Cancer: The Influence of Race and Sex,” Epidemiology, Vol. 23, No. 6, 2012, pp. 821-828. doi:10.1097/EDE.0b013e31826b7fe9

[5] M. Olivier, M. Hollstein, H. H. Schmeiser, K. Straif and C. P. Wild, "Upper Urinary Tract Urothelial Cancers: Where It Is A:T,” Nature Reviews Cancer, Vol. 12, 2012, pp. 503-504. doi:10.1038/nrc3311

[6] R. S. Malek, A. Moghaddam, W. L. Furlow and L. F. Greene, "Symptomatic Ureteral Stumps,” Journal of Urology, Vol. 106, 1971, pp. 521-528.

[7] T. Suzuki, N. Tsuchiya, R. Otomo, et al., "Primary Tumor of the Ureteral Stump Following a Nephrectomy for Renal Cell Carcinoma,” International Journal of Urology, Vol. 6, No. 1, 1999, pp. 41-43. doi:10.1046/j.1442-2042.1999.06124.X

[8] H. Y. Yang, J. D. Wang, T. C. Lo and P. C. Chen, “Occupational Exposure to Herbs Containing Aristolochic Acids Increases the Risk of Urothelial Carcinoma in Chinese Herbalists," Journal of Urology, Vol. 189, No. 1, 2013, pp. 48-52. doi:10.1016/j.juro.2012.08.090

[9] H. M. Pollack, M. P. Banner and G. L. Popky, "Radiologic Evaluation of the Ureteral Stump,” Radiology, Vol. 144, No. 2, 1982, pp. 225-230.

\author{
Abbreviations \& Acronyms \\ PUC $=$ primary urothelial carcinoma \\ RCC $=$ renal cell carcinoma \\ $\mathrm{RBC}=$ red blood cell \\ HGB $=$ hemoglobin \\ FBG $=$ fasting blood glucose \\ $\mathrm{CT}=$ computed tomography \\ WHO $=$ World Health Organization \\ $\mathrm{H} \& \mathrm{E}=$ HemateinEosin staining
}

